\title{
O racismo, a moda, e a diversificação dos padrões de beleza: o exemplo de Iman, top model Somali dos anos 70/80
}

\author{
Joana Passos $^{1}$ (iD 0000-0003-4357-1068 \\ 'Universidade do Minho, Instituto de Letras e Ciências Humanas, Centro de Estudos \\ Humanísticos/Centro de Estudos Feministas, Braga, Minho, Portugal.
}

4710-057-ceh@ilch.uminho.pt

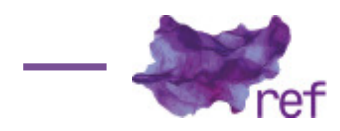

Resumo: Muito do trabalho desenvolvido por pensadoras feministas dos anos 70 aos anos 90 teve por objectivo denunciar a forma como a sociedade patriarcal não respondia as várias necessidades das mulheres nela inseridas. Nos anos 90 , o debate feminista diversificou-se em termos geopolíticos, incluindo questões de raça, religião e multiculturalismo. Ao mesmo tempo, promoveram-se estilos de vida alternativos, normalizando diferentes modelos de género. É no âmbito desta última prática que se coloca a questão de figuras precursoras. Quem mudou a noção do que é socialmente aceitável? Quem estabeleceu novas possibilidades? A minha investigação centra-se no mundo da alta costura, esfera com um forte apelo internacional, promovendo ideais de beleza e elegância. O caso de estudo que proponho constitui uma história de superação de padrões racistas na moda. A minha comunicação explora a carreira de Iman, modelo Somali que se tornou uma das estrelas de casa Yves Saint Laurent, nos anos 70/80, quando poucas modelos pretas tinham visibilidade nesse mundo. Hoje em dia, Iman está radicada na América, e tem mantido um discurso público sensível às questões de racismo no mundo da moda. Revisitar o seu testemunho é importante para reflectir sobre a necessidade de diversificar noções de beleza e denunciar a marginalização de diferentes grupos de mulheres face aos mais promovidos padrões de elegância e glamour.

Palavras-chave: racismo; norma e inovação; modelos de género; moda e glamour.

Racism, Fashion and Diversity In Beauty Patterns: Iman, Somali Top Model From The 70/80s Abstract: The aim of the work by many feminist thinkers from the 70s to the 90s was to expose the ways patriarchal societies did not live up to the needs and expectations of the women. From the 1990s onwards the feminist debate diversified its geopolitical scope so as to include issues related to race, religion and multiculturalism, while promoting alternative lifestyles. Thus, new gender models became established due to the impact of pioneering figures who changed the limits of what was socially accepted, establishing new possibilities. My research addresses the fashion world, an area of activity with high international impact, responsible for establishing patterns of beauty and elegance. I will address a case study which surpasses racism in the fashion world. My communication explores four biographies and an interview with Somali top model Iman, a star at Yves Saint Laurent in the 70s/80s, when few black models were integrated in the world of high fashion. Currently, Iman lives in America and she has kept a public discourse sensitive to issues of racism in the fashion world. Iman's testimony is important to reflect on the necessity of diversifying beauty ideals and expose the marginalization of groups of women from the most promoted patterns of elegance and glamour.

Keywords: racism; gender models; norm and innovation; fashion and glamour.

A motivação para escrever este artigo passa pelo meu papel como mãe e professora ao constatar como as adolescentes são profundamente influenciadas pela moda e pela publicidade na sua procura de autodefinição, isto é, na construção da sua noção de si. A noção do belo, ou da elegância, ou de beleza feminina, é algo que a maioria das adolescentes almeja, e esta 
procura de modelos de si pode tornar-se mais uma componente ofensiva e castradora para uma jovem adolescente (e para mulheres mais velhas também), quando, num país multirracial como o Brasil, se valorizam certos tipos étnicos como o modelo de beleza, em desfavorecimento da diversidade dos tipos de beleza que efectivamente existem. Se este artigo parece fútil, peço aos leitores que pesem o impacto da mídia e o número de indivíduos sensível a questões de moda e beleza. Todo um império económico global vive em torno dessa "fútil" questão, que é, isso sim, um poderoso mecanismo de exclusão social e a causa de uma séria ferida na parcela de narcisismo necessária a uma saudável definição da noção de identidade individual, inscrita, sempre e necessariamente, em interacção com o mundo social colectivo e os seus discursos e ideologias dominantes.

Num país como o Brasil, onde reside uma significativa população negra, ${ }^{1}$ pergunto que tipo de mensagem enviam as próprias instituições brasileiras a todas as adolescentes/mulheres que não se reveem, por exemplo, na imagem de Gisele Bündchen desfilando na abertura dos jogos Olímpicos no Brasil, 2016, ao som de Garota de Ipanema (Tom Jobim e Vinicius de Moraes, 1964), como se a sua beleza loura e branca fosse o ex-líbris do Brasil. Sublinho que, nesse contexto, cerimónia de abertura de um evento internacional acolhido pelo Brasil, não é a imagem da jovem que inspirou Jobim e Moraes que deve ser recordada. A imagem da mulher brasileira é que é evocada: trata-se da apresentação do Brasil ao mundo, não da biografia de um artista (a mulher que teria inspirado a canção seria a modelo, branca e alourada, Heloísa Pinheiro).

Como pensadora feminista portuguesa, com várias colaborações com colegas do Brasil e, por isso, um pouco consciente da realidade brasileira, lembro-me de ter pensado imediatamente que a imagem de Bündchen não representava a mulher brasileira em toda a sua diversidade. Mesmo tendo em conta a extraordinária carreira dessa modelo, essa escolha, nesse contexto, evoca uma longa história de racismo silenciado na sociedade brasileira.

No desenrolar deste artigo começo por discutir questões de racismo na sociedade brasileira. A seguir, abordo a força dos modelos identitários, que tanto podem ter uma função opressiva como uma função liberadora, e avanço dois exemplos de modelos liberadores concebidos por pensadoras feministas: a americana Donna Haraway e a sua teoria ciborgue, e a filósofa Rosi Braidotti (1994) e a sua figura do nómada.

Por fim, exploro um exemplo concreto da história do mundo da moda europeia e americana, a famosa modelo Iman, uma das primeiras modelos pretas ${ }^{2}$ que desfiou no elitista mundo da alta costura, $^{3}$ e que provou, pela sua produtiva e bem-sucedida carreira, que a indústria da moda pode representar a diversidade da beleza feminina sem, com isso, sacrificar a sua eficácia comercial. A sua biografia publicada e um livro de conselhos de moda para "mulheres de cor" (expressão usada nessa publicação, a partir da palavra inglesa "coloured") serão os nossos guias no confronto com os preconceitos da indústria da moda e de luxo. Sublinhe-se que, décadas mais tarde, ao verificar a persistência de preconceitos racistas na moda e nos mídia, Iman se tornou, juntamente com Naomi Campbell, a impulsionadora de uma campanha internacional ("Diversity on Runway") contra a prevalência destes preconceitos. Hoje em dia, o debate em torno do racismo e a favor da diversidade é corrente no mundo da moda, e esperemos que tenha consequências efectivas.

Segundo Antonio Sérgio Alfredo GUIMARÃES (2004), a história do desenvolvimento de uma consciência social das práticas racistas na sociedade brasileira é longa e complexa. Até aos anos 70, não se falava de racismo no Brasil. Falava-se de preconceito de cor, que radicava numa desculpabilização da discriminação a partir do pressuposto, tautológico, de que os negros eram pobres porque não conseguiam ascender socialmente, logo, não era uma questão de racismo, mas de classe social. O que era preciso fazer era minimizar a pobreza. Mas, como refere Guimarães citando Blumer, são quatro os sentimentos que estarão sempre presentes no preconceito racial do grupo dominante: (a) de superioridade; (b) de que a raça subordinada é intrinsecamente - diferente e alienígena; (c) de monopólio sobre certas vantagens e privilégios; e (d) de medo ou suspeita de que a raça subordinada deseje partilhar as prerrogativas da raça dominante (2004, p. 17-18). Esta é uma visão racista do mundo, mas, no caso da sociedade brasileira, foi pela luta de classes levada a cabo pela intelectualidade alinhada com uma agenda política de esquerda que os direitos da população negra começaram a fazer parte da agenda política.

Se recuarmos um pouco no argumento de Guimarães, é curioso como o autor aponta que já o modernismo brasileiro, movimento artístico dos anos 20, centrado sobretudo na cidade de São

\footnotetext{
' No Brasil, 51\% da população são de ascendência "negra africana", ou seja, a maioria, segundo site oficial do Governo do Brasil (http://www.brasil.gov.br/governo/2009/1 1/populacao acedido a 5 de abril, 2018). Comparativamente, para referir um outro exemplo conhecido, os Estados Unidos da América têm 13,3\% de população afro-americana segundo o censo de 2010 (https://www.census.gov/quickfacts/fact/table/US/PST045216 acedido a 5 de abril, 2018), e esta percentagem tinha subido para 14,5\% em 2016 (http://blackdemographics.com/, acedido a 5 de abril, 2018). 2 Uso o termo "preto/preta" para referir indivíduo/a com traços de afrodescendente. Uso o termo "negro/negra" quando estou a citar as ideias de um autor ou autora que usa esse termo nos seus trabalhos.

${ }^{3}$ A primeira mulher preta na capa da "Vogue" americana foi Beverly Johnson, que apareceu na capa do número de agosto de 1974. Iman irrompeu no mundo da moda um ano mais tarde, em 1975.
} 
Paulo, recupera a imagem do índio e referências da cultura popular para enraizar a identidade brasileira na diferença face aos padrões modernistas europeus. E, no entanto, esta procura de raízes autóctones é feita pela negação dos fortes elementos africanos da cultura nordestina, que nunca lhes interessou particularmente:

É que, no começo dos anos 1920, a revolução estética modernista já inventara o primitivo brasileiro, o popular, sob a influência das emoções trazidas pelos novíssimos espetáculos de massa europeus e de seu gosto pelo exótico - o modernismo artístico já desembarcara no Brasil pelo porto de Santos e fora gulosa e rapidamente consumido pelas vanguardas intelectuais paulistas, em busca, a um só tempo, de autenticidade e de sintonia com a Europa. O pensamento político que subjazia a essa elite, o seu declarado culto pelo imigrante, pela industrialização e pela urbe moderna, era de todo antagônico à lembrança do passado colonial luso-brasileiro do decadente Nordeste (GUIMARÃES, 2004. p. 13).

Ou seja, segundo Guimarães, o Brasil, demorou a confrontar-se com o seu próprio racismo, até se admitir nas esferas social e política que o racismo, enquanto princípio de discriminação, era anterior à relação entre "classe" e "raça" porque ao racismo já determinava a inserção de partes da população nas classes sociais mais desfavorecidas. O grande teórico a confrontar o Brasil com estas questões teria sido Carlos HASENBALG (1979), que afirmou (citado via Guimarães):

O racismo, como construção ideológica incorporada em e realizada através de um conjunto de práticas materiais de discriminação racial, é o determinante primário da posição dos nãobrancos nas relações de produção e distribuição (HASENBALG, 1979, p. 114, apud GUIMARÃES, 2004, p. 26).

Ou seja, mesmo com a abolição da escravatura, uma dada visão simbólica do mundo permaneceu intacta, e as práticas racistas do grupo dominante branco continuaram a perpetuar formas de subordinação funcionalmente relacionadas aos benefícios materiais e simbólicos que o grupo branco obtém da desqualificação competitiva dos não brancos (HASENBALG, 1979, p. 85). 0 desafio para ultrapassar esse estado de coisas é, segundo Guimarães (2004), descobrir os micromecanismos de discriminação, no âmbito da escola, do livro didático, da sala de aula, da mídia, da propaganda, dos locais de trabalho, dos locais de consumo e do mercado de trabalho (p. 28).

Se acrescentarmos o eixo discriminatório do sexismo, aliado às questões de racismo e da abissal diferença de classes na sociedade brasileira, podemos considerar que a moda, a publicidade e os padrões de beleza dominantes também constituem (micro) mecanismos de discriminação tão argutamente apontados por Guimarães. Voltaremos a estas questões mais à frente.

Partindo de um outro ponto de vista mais circunscrito a um estudo sobre educação no Brasil, Petronilha SILVA (2007) refere que não se pode "fazer vista grossa para as tensas relações étnicoraciais que 'naturalmente' integram o dia-a-dia de homens e mulheres brasileiros" e não "tomar conhecimento de que a sociedade brasileira projeta-se como branca" (p. 492-493). Considero que as palavras de Petronilha Silva ecoam o pensamento de Guimarães (2004), e completam uma visão crítica da sociedade brasileira que denuncia as suas práticas racistas.

Na sequência dos seus estudos sobre educação, Petronilha Silva (2007) conclui que:

A instrução pública, entre nós, nasce excludente, racista. A discrepância entre valores proclamados e valores reais da educação brasileira, apontada por Anísio Teixeira (1961) e também por Sander (1977), é persistente ao longo da história. [...] a escola, embora concebida, nos termos dos textos legais e objetivos pedagógicos, para garantir e divulgar princípios de justiça e igualdade, tem divulgado e reforçado visão unitária e não plural de sociedade. Tem propiciado a formulação de representações que desvalorizam os diferentes, aqueles que não se encaixam nos padrões difundidos pela referida visão unitária. Tem propiciado representações que geram, junto aos diferentes, tidos como não iguais, percepção de inferioridade que lhes seria inata e quase sempre incorrigível (p. 496).

Tendo em conta as palavras de Guimarães e de Petronilha, talvez não pareça então ser questão fútil questionar o impacto de ver a loira e bela Gisele Bündchen desfilar sozinha na cerimónia de abertura dos Jogos Olímpicos sem outras, três ou quatro companheiras, que, juntamente com Bündchen, invocassem a diversidade racial do Brasil.

Uma imagem/figura pública tem um impacto que se reflecte nas formas de pensar ou estar desse mesmo público, que a admira, e que com ela se identifica. Por isso, a difusão, culto e empoderamento de modelos afrodescendentes, índias ou mestiças, terá, à luz do que acima foi dito, um salutar impacto na sociedade brasileira.

Aliás, há muito que os movimentos dos negros do Brasil cultivam a sua galeria de mitos fundadores, como modelos de resistência social e política. Segundo Flávia RIOS (2012), a tradição negra de protesto político no Brasil tem vários momentos fundamentais, que são marcos dessa história particular, nomeadamente, o protesto realizado nas escadarias do Teatro Municipal de São Paulo, em 1978, conhecido como o ato do Movimento Unificado Contra a Discriminação 
Racial (MUCDR); de seguida, destacam-se as "As marchas do centenário da Abolição", em 1988, em várias cidades brasileiras; alguns anos mais tarde realizou-se "A marcha do tricentenário de Zumbi dos Palmares" - 1995 (movimento nacional com passeatas em várias cidades) e, por fim, instituiu-se a "Marcha Nocturna pela Democracia Racial" (que toma lugar em São Paulo, desde 1996). É no decorrer destas manifestações que se verificou que os activistas começaram a compreender o poder de certas figuras de referência, como modelos inspiradores do movimento de activismo político contra o racismo:

A ideia da "falsa abolição" ou "abolição inacabada" é o slogan das últimas marchas; a passeata também conta com grandes fotografias de heróis e pessoas ilustres impressas em banners. Assim, as figuras de abolicionistas - como André Rebouças, José do Patrocínio, Luis Gama - e de líderes de revoltas do Brasil escravagista - como Zumbi e Luiza Mahim - são particularmente reverenciadas. Esses últimos figuram no repertório do movimento como a imagem da resistência negra e da liberdade. [...] As imagens desses heróis são colocadas lado a lado com líderes do movimento negro do século XX, como Adbias do Nascimento (1914-2011), Lélia Gonzalez (1935-1994) e Hamilton Cardoso (1954-1999), dentre outros (RIOS, 2012, p. 72).

Mas não só os momentos políticos mais formais exploram o poder de determinadas figuras públicas. É claramente reconhecido, e muitas vezes pago a peso de ouro, o impacto de algumas figuras públicas, entre elas as modelos de moda. Nos EUA, uma outra nação americana que também tem uma significativa população afrodescendente, o número de agosto da "Vogue" de 1974 fez história: Beverly Johnson foi a primeira mulher preta a aparecer na capa dessa famosa revista americana (que já existia desde 1909). Não quero, com isto, dizer que exista qualquer proporcionalidade entre públicos e diversidade de modelos, ou que desde então a "Vogue" deixou de ser uma revista sobretudo dirigida a um público de élite. Mas alguma regra implícita foi quebrada ao fazer-se algo tão diferente como escolher o rosto de Beverly Johnson para a capa, o que desde então abriu outras possibilidades para subsequentes editores. Mais importante do que isso, o público branco, norte-americano, foi confrontado com a "normalização" da beleza das mulheres não brancas, e este facto tornou-se um dado adquirido e reconhecido no discurso público. Para a população afrodescendente algo mais radical aconteceu: não tinha de ser representada como um grupo empobrecido, sem acesso a bens de luxo ou glamour. E é isso que é celebrado nas revistas norte-americanas que apostam em modelos pretas: a existência de uma classe média afrodescendente, com acesso às mais prestigiadas universidades e às subsequentes carreiras liberais, o que Ihes permite comprar bens de luxo. E a representação deste poder económico e desta mobilidade social é importante em termos de autoimagem da própria comunidade afrodescendente.

Creio que de tudo o que acima foi dito se pode concluir que sempre se criaram "figurasmodelo" que serviam de referência para moldar ou influenciar comportamentos públicos. Já seria esse o caso, por exemplo, das divindades ou mitos clássicos. Da mesma forma, o debate feminista tem uma vertente que se tem vindo a debruçar não só sobre a desconstrução de mitos sexistas mas também sobre a criação de novos mitos ou figuras que materializem as novas ideias e novas utopias propostas pelos estudos feministas e pelos estudos de género.

Para se definir o "novo", temos de revisitar o que era o "tradicional". Uma visão tradicional do mundo estava rigidamente dividida entre homens e mulheres, a quem se atribuíam determinadas características e papéis sociais. No fundo, uma visão racista também funciona desta maneira, mas, neste caso, o eixo de diferenciação é "branco" e "não branco".

Luce IRIGARAY (1977) afirmaria que numa sociedade baseada na diferença sexual, a valorização do elemento masculino funciona em detrimento do valor ou do reconhecimento colectivo que é atribuído aos elementos femininos dessa mesma sociedade. Sabemos hoje que existem vários géneros, e que as formas de se ser e de se estar no mundo não se reduzem ao esquema binário que divide o mundo entre homens e mulheres, entre masculino e feminino. No entanto, permitam-me recuperar um pouco as teorias de diferença sexual de Luce Irigaray para poder ilustrar o meu argumento. Ao atribuir a cada género (ou raça) uma posição numa dada hierarquia está-se a gerir a distribuição do poder e o acesso a bens. $E$, muitas vezes, um dos principais eixos de desigualdade, que desde logo marginaliza uma parte da população ao acesso a privilégios e bens, baseia-se em diferenças de género. Por muito que hoje se acuse Luce Irigaray de essencialismo, a verdade é que a grande maioria dos pobres do mundo são mulheres, ao ponto de a Unesco ter vários programas de requalificação das mulheres no âmbito da luta desta organização para erradicar a pobreza.

No caso concreto da diferença sexual, a forma de destabilizar uma tradicional visão binária do mundo passou por apoiar a proliferação de géneros, integrar transsexuais, legalizar o casamento de pessoas do mesmo sexo, e assim alterar o modelo de família nuclear. Ou seja, ao complicar-se esquemas explicativos limitados e rígidos pela promoção das diferenças e da diversidade, a credibilidade de esquemas binários rígidos é reduzida. A variabilidade, a existência de múltiplas possibilidades num qualquer esquema de organização é, em si, subversiva e liberadora. Daí 
advém a importância de criar novos mitos, que afirmem novas possibilidades de se encarar o corpo, escapando a classificações tradicionais. Veja-se, por exemplo, o muito famoso caso do Manifesto Ciborgue (Donna HARAWAY, 2000). O ciborgue como mito popular contemporâneo representa a fusão entre o humano e a máquina, ou entre o biológico e a técnica. Um ciborgue não teve pai nem mãe, não existe dentro de uma estrutura familiar tradicional, não tem sexo definido, e pode até ser assexuado. Tudo depende das componentes com que o quisermos construir. Se o ciborgue fosse um mito de laboratório, não teria o apelo popular que tem, nem estaríamos aqui a reflectir sobre este assunto. Por um lado, associado ao desenvolvimento militar, o ciborgue é uma imagem temível, mas existe toda uma filmografia muito bem-sucedida junto do público, em que o ciborgue é alguém com alguma capacidade a mais, alguém optimizado, transformado num super-humano. No mundo tecnológico em que vivemos, a proximidade do ciborgue com componentes mecânicas parece confortável, desejável. De certa forma, a popularidade da cirurgia plástica (estética) no mundo de hoje já é uma materialização desse desejo de nos melhorarmos pela fusão com a tecnologia.

Mas os estudos de mulheres também têm estado presentes na encruzilhada de questões de género e de raça como eixos discriminatórios que se cruzam e se sobrepõem. Gostria de sublinhar que o propósito de uma evolução fundamental nos estudos feministas ocorreu a partir do anos noventa, quando se reconheceu que diferentes grupos de mulheres, situados em diferentes culturas ou classes sociais, aspira a diferentes alterações na sua vida. Quer isto dizer que o feminismo não pode aspirar ser uno, nem totalizante: existem feminismos, e diferentes agendas e prioridades, adequados à situação de diferentes mulheres. E existem também questões transversais a vários grupos, que dão coesão a um mais variado e global movimento de mundos de mulheres. Também neste caso, uma pensadora feminista que me é particularmente cara reinventou a figura do nómada, atribuindo-lhe um potencial provocador e subversivo. Refiro-me à Rosi BRAIDOTII e à sua figura do nómada do século XXI. Pensar "como um nómada" é pensar a partir de uma posição minoritária, mas com uma distância crítica (a do viajante, de quem está de fora) que permite maior consciência das inconsistências e falhas da sociedade onde estamos, como se a víssemos com o estranhamento do viajante, como quem está de passagem. Mas, ao mesmo tempo, o nómada precisa conhecer suficientemente bem as sociedades por onde passa para se mover eficazmente nos seus meandros, pois ele é um sobrevivente. Por fim, a figura do nómada é um mito que nos permite imaginar o estrangeiro em termos positivos, como aquele que vê e entende mais do que o habitante local, porque o nómada observa e compara diversas realidades. Mas ser nómada é também estar em trânsito, em constante movimento. Por isso, o nómada não é "domesticável", não aceita o que está estabelecido como certo, relativizando tudo e todos.

Quer o ciborgue quer o nómada são mitos fundadores para se pensar novas intervenções políticas e novas formas de activismo no século XXI. Na mesma senda, em articulação com os mitos idealizados pelas duas académicas acima mencionadas, queria levantar a questão da existência de figuras de referência nos media, tais como actores, cantores e modelos que, na cultura popular, assumem o mesmo papel inspirador que os mitos acima reinventados. A título de exemplo, vou debruçar-me sobre um caso icónico no mundo da moda, a modelo Iman, muçulmana natural da Somália, que iniciou a sua carreira em 1975, quando foi convidada para fazer parte de uma agência de modelos em Nova York. O seu notável percurso profissional quebrou muitas barreiras invisíveis nesse mundo fechado e selectivo, tendo-se tornado na musa de Yves Saint Laurent uma das principais casas de moda de Paris nessa época. Para além da sua carreira, que vale pelo exemplo e pelo encorajamento que representa, Iman tem igualmente lutado de uma forma explícita contra o racismo no mundo da moda.

Para se ter uma ideia de como Iman conseguiu desbravar um caminho improvável, a modelo refere, no seu livro autobiográfico, I Am Iman (2001), que quando foi "descoberta" pelo fotógrafo americano Peter Beard (a este respeito, Iman sempre diz que não percebe por que dizem que foi "descoberta", porque não estava nem perdida nem escondida) foi necessário criar uma história inventada para a apresentar ao mundo da moda de Nova York. Aparentemente, uma beleza africana só podia ser aceite no mundo da moda ocidental como representante do exotismo, uma curiosidade para um olhar eurocêntrico e racista. Assim, foi dito aos jornalistas que Iman teria sido descoberta na savana, e nem falava inglês. Iman deixou que se montasse a campanha, chegou a Nova York onde era suposto traduzirem as perguntas dos fotógrafos para si, e, a meio da conferência de imprensa, resolveu começar a falar em inglês e responder a tudo como bem pensava. O espírito crítico por detrás da rebeldia terá feito a diferença em relação a outros modelos, e captou a atenção dos criadores.

Depois de uma fulgurante carreira na moda, Iman abandonou as passerelles 19 anos mais tarde, em 1989. Fundou uma empresa de cosmética para "mulheres de cor" (a expressão que uso é traduzida do inglês, "coloured women", que é a que é usada no livro), a Iman Cosmetics, hoje em dia avaliada em 25 milhões de dólares. Também desenhou uma linha de decoração de interiores, fez alguns papéis menores no cinema e casou com o músico David Bowie, com quem viveu mais de 20 anos, até a morte dessa famosa estrela do rock. 
Um dos exemplos do activismo de Iman é a sua recente campanha "Diversity on Runaway", ou a "Diversity Coalition", da qual também participa Naomi Campbell. ${ }^{4} \mathrm{O}$ objectivo desta campanha é denunciar uma hierarquização da beleza feminina, sendo o modelo de referência - portanto o preferido - a loura de olhos azuis. Ora, a questão é que ao dizer-se repetidamente nos media que as mulheres mais belas são louras e têm olhos claros, o que não se diz explicitamente, mas acaba por ser reafirmado, é que a raça branca é "superior". Ou seja, a partir de uma questão de estética, existe uma política do mundo da moda que não é nem inocente, nem acidental, porque a moda é uma indústria que vai de encontro a mentalidades dominantes, pois quer cativar um público numeroso e rico. Por isso, toda a indústria da moda tem uma mensagem conservadora e racista, que agrada à classe média e que desculpabiliza os seus preconceitos entranhados, em lugar de os confrontar ou questionar. Para as adolescentes de todo o mundo que não são brancas, e que normalmente ligam muito à moda, a mensagem que recebem através dos media globais não é positiva, nem promove a sua confiança e autoestima. Para contrariar esta repetição de discursos racistas, difundidos de uma forma discreta e perigosamente subliminar, é necessário que, tal como no caso do ciborgue ou do nómada, se incentivem novas práticas que apontem caminhos para uma imaginação alternativa, valorizando o que antes se marginalizava ou rejeitava. Dessa forma, afirma-se o valor da diversidade. Pelo contrário, a ausência de modelos de cor nos desfiles dos principais costureiros cria uma estrutura de pensamento binária em que a noção do belo coincide com a raça branca, remetendo à invisibilidade todas as demais raças, como se estivessem marcadas com uma negatividade ou uma falha.

Já Toni MORRISON, a grande escritora americana, prémio Nobel da literatura em 1993, escreveu um livro sobre este mesmo problema social. Refiro-me a The Bluest Eye (19705), um livro extremamente controverso que acompanha o desenvolvimento de um complexo de inferioridade numa jovem adolescente preta que sonhava ser branca e ter olhos azuis. A grande depressão de 1930 e as suas consequências sociais servem de pano de fundo para ilustrar as dificuldades da comunidade afrodescendente e a vulnerabilidade das crianças que crescem sem protecção face a vários tipos de abuso. No caso concreto da jovem personagem principal deste romance, ter olhos azuis é metáfora do desejo de "ser branca", pois essa aparência parece proteger outras crianças da falta de amor e da violência que rodeiam a protagonista. Ou seja, a partir de uma questão de aparência, todo um mundo social e todo um percurso de vida (quase que "predestinado") são denunciados pela mão de Toni Morrison . O romance em questão foi traduzido para o português em 2003 como O Olho Mais Azul.

Tal como a escrita de Toni Morrison, o activismo de Iman é um exemplo que nos faz acreditar que todos podemos contribuir com as nossas palavras e gestos para tentar mudar o que está errado no mundo.

A autobiografia de Iman, I Am Iman (2001), é uma história de sucesso, a começar pelo próprio livro, um artigo de luxo, pejado de fotografias pelos mais prestigiados fotógrafos: Helmut Newton, Peter Beard, David Bailey e Bruce Weber. O livro está dividido em capítulos ${ }^{6}$ que focam vários aspectos da vida e carreira de Iman. As fotografias incluídas no livro e o cuidado gráfico (com a colaboração de designers) posto em cada página são em si evidência de um investimento na celebração de uma figura de culto. Vários dos textos são escritos por amigos e colaboradores que acompanharam o percurso da modelo, o que é muito mais interessante do que ter um único testemunho. O resultado é uma história contada a várias vozes, em que um percurso biográfico é usado para discutir outros assuntos. Por exemplo, o fotógrafo americano que supostamente descobriu Iman, Peter Beard, é entrevistado para o livro (páginas 26 a 33). Alguns dos seus comentários são muito contundentes: "The word 'racism' should be reexamined, what it really means is territorialism" (IMAN, 2001, p. 25). ${ }^{7}$

Da mesma forma, Beard admite que a verdadeira razão para procurar uma modelo africana em 1975 tinha a ver com uma ideia de exótico, um exótico que tinha de ser "autêntico" para agradar aos olhos ocidentais: "We (Vogue) wanted authenticity. That's what we're lacking [...] Iman came with her amazing neck and poise and her elegance and her authenticity" (IMAN, 2001, p. 28). ${ }^{8}$

A própria Iman assumiu muitas vezes que ser africana lhe abriu as portas da moda americana. Era estrangeira, era o exótico autêntico. Uma curiosidade. Não punha em causa as barreiras de classe e poder entre americanos e afro-americanos. Mas Iman era uma observadora

\footnotetext{
4 Ver https://www.youtube.com/watch?v=mVRXWaWrmqM. Ver também https://www.youtube.com/ watch?v=0gWBa9ATaA.

${ }^{5}$ New York: Holt, Rinehart and Winston, 1970 (Primeira Edição).

${ }^{6}$ Cap. I - Africa, my Africa; Cap. II - Escape to Kenya; Cap. III - Exile on Main Street; Cap IV - The Circus comes to Town; Cap. V - The New Girl Next Door; Cap. VI - The African and the Alien; VII - Photo Gallery.

7 "A palavra 'racismo' devia ser revista. O que quer dizer realmente é territorialismo" (minha tradução).

8 "(Na Vogue) procurávamos autenticidade. Era isso que nos faltava [...] e Iman chegou com o seu espantoso pescoço, aquela pose, a sua elegância e a sua autenticidade" (minha tradução).

${ }^{9}$ Ver https://www.youtube.com/watch?v=O_J7L_eODfw\&t=62s.
} 
atenta e como afirmou numa entrevista a Ernie Marnouse:9 "As políticas do mundo da moda não se perderam em mim". Nessa mesma entrevista, Iman afirma que era diferente ser de Àfrica ou das Caraíbas ou ser afro-americana. Muitas belezas afro-americanas que podiam fazer o mesmo trabalho que Iman estavam em Nova York, e não conseguiam emprego. Ao ter uma oportunidade no mundo da moda, Iman aproveitou-a, tendo admitido a sua cumplicidade com este meio, o qual the permitiu enriquecer e tornar-se famosa. Mas, ao mesmo tempo, também resolveu ir confrontando este mesmo mundo ao longo dos anos, não se fechando nos privilégios da sua sorte individual. Toda a consciência política revelada nessa mesma entrevista a Marnouse enquadra os livros de Iman e consolida o tipo de discurso que aí é exposto. De certa forma, o livro que aqui se discute é uma réplica deste mesmo percurso biográfico. I Am Iman trata-se de um livro com um aspecto sofisticado, destinado ao mais elitista público da moda - que é coleccionador, que quer guardar este livro (capa dura, a cores, papel de qualidade, tamanho grande, pesado) na sua biblioteca ou arquivo. E, no entanto, este mesmo livro transmite, com toda a frontalidade, uma mensagem contra o racismo, precisamente para um público onde militantes serão improváveis. De certa forma, Iman subverte as expectativas de quem compra este tipo de livro, pois é um livro político, embrulhado numa capa de glamour. Tal como a pessoa por detrás do modelo. neste livro:

Durante toda a vida, Iman ouviu comentários supostamente elogiosos, aos quais responde

"É tão bonita que parece uma branca molhada em chocolate"

"É tão bonita que deve ser meia-branca"

"Ora bem, eu não sou meia branca. Não tenho uma gota de sangue branco em mim. Sou bonita porque sou preta, e sou da Somália" (IMAN, 2001, p. 118).

Este discurso de autoafirmação é tão necessário como útil, e pode tomar muitas outras formas, como motivar as jovens afrodescendentes a sentirem-se bem na sua pele. Foi esse o objectivo de um outro livro lançado por Iman, com conselhos de maquilhagem e de higiene para mulheres não brancas (na capa do livro posam Iman, modelo preta, uma modelo que sugere ascendência chinesa e uma modelo latina). Em The Beauty of Colour Iman (2005) prova que beleza não é "all white" ao reunir um conjunto de modelos das mais diferentes raças, inluindo modelos de ascendência mista. A beleza que desfila nas páginas deste livro é inegável, e cada modelo é acompanhada por conselhos tendo em conta o seu tipo de pele, de olhos ou de boca. Para além da pontual lição de maquilhagem, o verdadeiro alcance do livro é equilibrar as referências de beleza disponíveis nos media, ao mesmo tempo em que se promove a autoestima de mulheres em todo o mundo, encorajando-as a pensar em si, e possivelmente a agir de uma forma mais liberada, no sentido de terem a percepção dos seus direitos e das suas ambições. Uma parte não menos importante deste livro são os testemunhos que reúne: Selma Hayek, actriz consagrada; Venus e Serena Williams, campeãs de ténnis; Ling, modelo; Naomi Campbell, modelo; Eva Mendes, actriz; Jade Jagger, modelo; Tyra Banks, modelo e apresentadora. Aparentemente todas estão a falar de maquilhagem, mas, algo mais está aqui representado. Um conjunto de mulheres de sucesso. Também é importante referir a repetida referência à mestiçagem e à celebração de beleza que advém de uma herança "African, Latin and Asian".

Por fim, uma referência à fotografia no centro do livro I Am Iman, nas páginas 102-103, que representa "Iman's tribe of beauties" (a tribo de belezas de Iman). A fotógrafa é Annie Liebowitz. Nessa fotografia aparecem dezassete belíssimas mulheres pretas, modelos consagradas. Não porque todas as mulheres são belas e são modelos de cor mas porque, como aponta Iman, em todo o tempo que trabalhou no mundo da moda assistiu a muitas fotografias com grupos de modelos brancas, ou com alguma diversidade étnica entre as mulheres representadas. Nunca as grandes casas de moda do ocidente fizeram uma campanha só com modelos de cor. A provocação que subjaz à composição desta fotografia é um claro exemplo do sofisticado activismo de Iman, e ilustra a forma como ela procura mudar as referências do mundo da moda.

\section{Referências}

BRAIDOTTI, Rosi. Nomadic Subjects. New York: Columbia University Press, 1994.

GUIMARÃES, Antonio Sérgio Alfredo. "Preconceito de cor e racismo no Brasil". Revista de Antropologia, São Paulo, USP, v. 47, n. 1, 2004.

HARAWAY, Donna. "A Cyborg Manifesto. Science, Technology and socialist-feminism in the Late Twentieth Century". In: BELL, David; KENNEDY, Barbara M. (ed.). The Cybercultures Reader. London: Routledge, 2000.

HASENBALG, Carlos. Race Relations in Post-Abolition Brazil, The Smooth Preservation of Racial Inequalities. Berkeley: University of California, 1979. 
IMAN. I Am Iman. London: Booth-Clibborn Editions Ltda., 2001.

IMAN. The Beauty of Colour. New York: A Perigee Book, 2005 (Pinguin Group)

IRIGARAY, Luce. Ce sexe qu'en est pas un. Paris: Éditions de Minuit, 1977.

MORRISON, Toni. The Bluest Eye. London: Chatto and Windus, 1970.

RIOS, Flávia. "O protesto negro no Brasil contemporâneo (1978-2010)". Lua Nova, São Paulo, n. 85, p. 41-79, 2012.

SILVA, Petronilha. "Aprender, ensinar e relações étnico-raciais no Brasil". Educação, Porto Alegre, ano XXX, v. 3, n. 63, p. 489-506, set./dez. 2007.

Joana Passos (jfvpassos@gmail.com) é doutorada pela Universidade de Utrecht, Holanda, em 2003, em Estudos Pós-Coloniais e Estudos Feministas. Tem trabalhado teoria da literatura e literaturas em língua inglesa e portuguesa (incluindo a literatura de Goa e literaturas africanas).

\section{COMO CITAR ESSE ARTIGO DE ACORDO COM AS NORMAS DA REVISTA}

PASSOS, Joana. "O racismo, a moda, e a diversificação dos padrões de beleza: o exemplo de Iman, top model Somali dos anos 70/ 80". Revista Estudos Feministas, Florianópolis, v. 27, n. 1, e58981, 2019.

\section{CONTRIBUIÇÃO DE AUTORIA}

Concepção, coleta e análise de dados, discussão dos resultados, elaboração do manuscrito e redação.

\section{FINANCIAMENTO}

Não se aplica

\section{CONSENTIMENTO DE USO DE IMAGEM}

Não se aplica

APROVAÇÃO DE COMITÊ DE ÉTICA EM PESQUISA

Não se aplica

\section{CONFLITO DE INTERESSES}

Não se aplica

\section{LICENÇA DE USO}

Este artigo está licenciado sob a Licença Creative Commons CC-BY. Com essa licença você pode compartilhar, adaptar, criar para qualquer fim, desde que atribua a autoria da obra.

\section{HISTÓRICO}

Recebido em 03/09/2018

Aprovado em 07/09/2018 